\title{
An airplane jig shape design method based on high fidelity aeroelastic simulation
}

\author{
Wei Yang ${ }^{\mathrm{a}, *}$, Qifeng Wang ${ }^{\mathrm{a}}$, Lei Zhou ${ }^{\mathrm{a}}$, Guannan Zheng ${ }^{\mathrm{b}}$, Wen Liu ${ }^{\mathrm{b}}$ \\ a Beijing Aeronautical Science \& Technology Research Institute, Commercial Aircraft Corporation of China, Ltd., China \\ ${ }^{\mathrm{b}}$ Institute of Mechanics, Chinese Academy of Sciences, China
}

\section{A R T I C L E I N F O}

\section{Article history:}

Received 20 June 2015

Received in revised form 28 September

2015

Accepted 1 October 2015

Available online 22 October 2015

\section{Keywords:}

Aeroelasticity

CFD

CSD

Jig shape

Structural mesh

\begin{abstract}
A B S T R A C T
This paper develops a jig-shape design method for the elastic wing of the commercial aircraft with high aspect ratio. Two optimization steps are involved in the design method to optimize the jig shape of the elastic wing with the user-desired cruise aerodynamic performance. The real aeroelastic simulation becomes the fundamental of the design procedure. Structural mesh based CFD solver has been applied to simulate the transonic flow with high fidelity. Finite element based structural model of wing with complex configuration is constructed, and the flexibility matrix is evaluated to predict the deflection of the wing. The high-efficient mesh deformation technique and the data exchange interface between CFD and CSD are implemented, which improves the efficiency and accuracy of current approach. The jig shape design of a baseline commercial aircraft is presented, and the numerical simulation shows that the design method is strong enough to obtain the optimized jig shape efficiently.
\end{abstract}

(c) 2015 Elsevier Masson SAS. All rights reserved.

\section{Introduction}

Aeroelastic distortion happens during aircraft flights under aerodynamic loads, which cause the bending and torsion of the wing and then changing the airflow on the wing surface, meanwhile changing the loads on the wing [1]. These alternate until the structure is in balance. Apparently, aeroelastic distortion has an important influence on aerodynamic performance, and the actual aerodynamic state is different from the design state [2]. The modern aerodynamic shape design should consider the static aeroelastic phenomenon, especially for the high aspect-ratio wing of commercial aircraft.

Since static aeroelastic is very important in aircraft design [3], a bunch of numerical simulations [4-6] and wind tunnel experiments [7-9] have been performed to study the static aeroelastic phenomena. As mentioned before, the cruise shape is much different from the jig shape because of the static aeroelastic deformation [10]. Normally, the aerodynamic design provides the cruise shape by CFD (Computational Fluid Dynamics) simulation and wind tunnel tests. Actually, a manufacture shape should deform to the cruise shape to promise the design aerodynamic capabilities. The jig shape, also named manufacture shape, will not

\footnotetext{
* Corresponding author.

E-mail address: vivi_yang3822@126.com (W. Yang).
}

change for an aircraft, but the tarmac shape will be different because of different fuel load [11-15].

Theoretically, the jig shape could be designed through wind tunnel tests, however it is too expensive to be realized. In fact, if the jig shape could not deform into the real cruise shape which meets all the requirements under the cruise state, the jig shape model must be reworked until all the conditions are satisfied $[16,17]$. Even though the jig shape could be designed through wind tunnel tests, however the experimental cost is very expensive, which hinders its wide application. Currently, the experimental cost is still a very heavy burden. Generally, the commercial aircraft manufactures design the jig shape based on CFD solvers and validate its feasibility by wind tunnel tests to reduce the cost.

Essentially, the jig shape design based on CFD solver becomes a coupling problem of fluid and structure. Many engineers and researchers have worked on the jig shape design. For example, Rohl et al. [18] incorporated several approximation tools in the determination of an un-deformed wing shape that deforms into its cruise shape under the cruise load condition. They used the Flight Optimization System code to give an initial wing jig shape, and used the wing design program WINGDES to determine the optimum twist and camber distribution. Unlike most of the previous design efforts, Reno et al. focused on wing optimization via control theory using a multi-point design method. The jig shape design actually was the static aeroelastic problem, so most design approaches perform aerodynamic and structural analyses iteratively. On the contrary, Aly et al. focused on a decoupled approach working on 
jig shape design method [19]. The coupled aerodynamic/structural analysis has been decoupled throughout the optimization process.

NASA and Boeing worked together on the project "Elastically Shaped Future Air Vehicle Concept" [20]. A static and dynamic aeroservoelastic model of the elastically shaped wing are developed, which is in conjunction with a flight dynamic model for analyzing aerodynamics, stability and control of the elastically shaped aircraft. Yang et al. [21] improved an efficient method for the jig shape design of a flexible wing based on the iterative correction method. Both twist and bending deflection distributions at each cycle are considered. This method was referred to as the twistbending correction method. By using a high-aspect-ratio wing as an example, the jig shape design process was demonstrated. Chen et al. [22] presented new developments in the capabilities of design-oriented (DO) Euler/boundary layer unsteady aerodynamic simulations to allow the accounting for static and dynamic aeroelastic constraints in the multidisciplinary shape optimization of flight vehicles based on ZUES software.

The structural deformation in static aeroelasticity is caused by lift mostly, so the aerodynamic pressure changes that result from the velocity and acceleration associated with structural deformation can be neglected. Therefore, the three-dimensional Euler equations without viscous effects are adopted in many aeroelastic studies. However, the purpose of the jig shape design is to get a real cruise shape after the static aeroelastic deformation, and the aerodynamic conditions of it are exactly just like the designed cruise shape. Therefore, high precision CFD simulation is very important to provide the effective pressure distribution over the wing surface of the aircraft. However, most of these previous experiences with jig shape design were without a high precision CFD model to provide accurate aerodynamic performance or the calculate time was too long to be brought into engineer design.

In the current work, an airplane jig shape design method with high aerodynamic precision is developed. Two optimization steps are involved in the design method to optimize the jig shape based on the unload jig shape of the elastic wing with the user-desired cruise aerodynamic performance. In addition, the CPU time needed in this design process is much shorter than that of the previous methods. And a baseline aircraft is selected to test the design method.

\section{CFD/CSD coupled static aeroelastic simulation method}

\subsection{The static aeroelastic simulation}

The static aeroelasticity studies the interaction of the aerodynamic loads over the aircraft structures surface and the deflection of the structure. The coupled calculation of aerodynamics load and structural deflection should be performed. Based on the assumption of small deformation, the structural deflection can be predicted by solving the following linear equations:

$$
[K] q_{s}=f_{s}
$$

where $[K]$ is the stiffness matrix, $q_{s}$ the nodal displacement and $f_{s}$ the aerodynamic forces. Note the inverse of the stiffness matrix becomes the flexibility matrix. If the stiffness matrix and aerodynamic force are given, the nodal displacements could be determined from eq. (1). The stiffness matrix is certain of the structure, and the aerodynamic force could be obtained by CFD analysis or wind tunnel tests.

Fig. 1 shows the procedure of static aeroelastic analysis, in which CFD calculation and CSD (Computational Structure Dynamics) simulation iterates until convergence. The convergent standard is:

$\epsilon=\left|\frac{\delta_{i}-\delta_{i-1}}{\delta_{i}}\right|<10^{-6}$

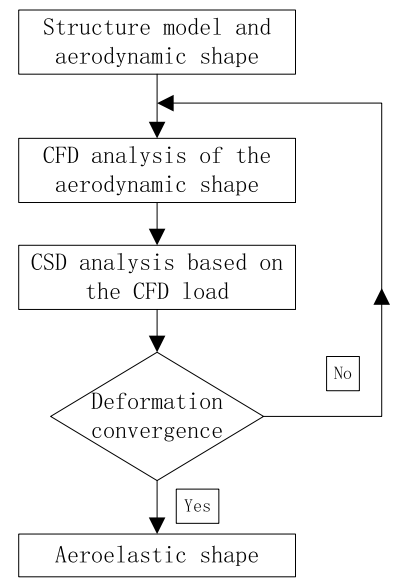

Fig. 1. Flowchart of a static aeroelastic calculation.

In which, $\delta_{i}$ is the biggest deformation distance of the current calculation, and $\delta_{i-1}$ is the biggest deformation distance in the last calculation.

In the calculation, high-fidelity CFD solver is used to predict the aerodynamic force, and flexibility matrix is constructed through FEM analysis. However, the activities include the development of efficient and robust CFD grid deformation tools, accurate threedimensional interpolation tools for transferring data between the CFD grids and the CSD grids as well as the implementation of suitable interfaces between the CFD solver and the FEM solver.

\subsection{Aerodynamic analysis}

A high precision CFD solver is employed in this study. It uses multigrid calculation procedure with structured meshes to discretize the governing Navier-Stokes equations for viscid compressible flow. Moreover, MPI (Message Passing Interface) is used to reduce the calculation time. The structured meshes need little memory on computer, and the results are more accurate in simulating the boundary layers then the unstructured meshes. It stores the flow data on central nodes, and the finite volume method, the ROE spatial discretization schemes, the LU-SGS implicit time marching method and SA/SST $k-\omega$ turbulent model are used. The initial density, velocity and pressure of the inlet flow are calculated by the given cruise state. The no-slip wall boundary is considered for viscous flow, in which the velocity of the wall nodes is zero.

For structured grid of 1500 million nodes, it takes about one hour on 96 CPUs to get a force convergent result.

\subsection{Structure analysis}

The finite element model is established based on MSC. Patran. By equation (1):

$q_{s}=[C] \cdot f_{s}$

where $[C]$ is the flexibility matrix, and $[C]=[K]^{-1}$.

MSC. Nastran is used for calculating the flexibility matrix. Firstly, select all the surface points on the deform structure; Secondly, give 1 unit force on these selected points at $x, y, z$ directions respectively and calculate all the $*$.bdf files to get the flexibility matrix from these $*$.f06 results. Actually, if the number of the surface points is too big, important surface points are chose that is no more than 1500 points usually. Once obtaining the flexibility matrix $[C]$, nodal displacement $q_{s}$ could be calculated quickly by equation (3) even during the iteration. 


\subsection{Three-dimensional interpolation between CFD and CSD}

A multivariate interpolation scheme using the Radial Basis Functions (RBF) [23,24] is implemented for the fluid-structure interpolation and mesh motion. This scheme allows an arbitrary deformation to be represented to within a desired tolerance by using a significantly reduced set of surface points intelligently identified in a fashion that minimizes the error in the interpolated surface. RBF interpolation defines the following formula:

$s(r)=\sum_{i=1}^{i=N} \alpha_{i} \phi\left(\left\|r-r_{i}\right\|\right)$

where $s(r)$ is the function to be evaluated at location $r$ and defines the motion of the volume points. $\phi$ the function adopted $[25,26]$, $i$ identifies the centre for the RBF, and $r_{i}$ the location of the centre. $\alpha_{i}$ is determined by requiring exact recovery of the original function at these volume points.

In current implementation, Wendland's C2 function is applied and

$\phi(\xi)=(1-\xi)^{4}(4 \xi+1)$

for its third order precision and high efficiency.

Based on the principle of virtual work, the following relation holds

$\left(\Delta \overrightarrow{\boldsymbol{X}}_{\mathrm{a}}\right)^{\mathrm{T}} \overrightarrow{\boldsymbol{F}}_{\mathrm{a}}=\left(\Delta \overrightarrow{\boldsymbol{X}}_{\mathrm{s}}\right)^{\mathrm{T}} \overrightarrow{\boldsymbol{F}}_{\mathrm{s}}$

where $\overrightarrow{\boldsymbol{F}}_{\mathrm{a}}$ is the CFD surface force, $\overrightarrow{\boldsymbol{X}}_{\mathrm{a}}$ the surface points vector of the CFD surface points, $\overrightarrow{\boldsymbol{F}}_{\mathrm{s}}$ the structural nodal force, and $\overrightarrow{\boldsymbol{X}}_{\mathrm{S}}$ the nodal vector of the finite element based structural model.

Based on RBF, the displacements of nodal points are determined $\Delta \overrightarrow{\boldsymbol{X}}_{\mathrm{s}}=\boldsymbol{C}_{\mathrm{ss}} \overrightarrow{\mathrm{A}}_{\mathrm{x}}$ and vice versa, $\Delta \overrightarrow{\boldsymbol{X}}_{\mathrm{a}}=\boldsymbol{C}_{\mathrm{as}} \overrightarrow{\mathrm{A}}_{\mathrm{x}}$ where $C_{\mathrm{ss}}$ and $C_{\mathrm{as}}$ are associated transfer matrix.

In summary, RBF features several significant advantages:

1) For the CFD/CSD coupling problem, only surface point clouds are required.

2) It can be applied to both of structured and unstructured grids without any connectivity information.

3) It has small computational amount and high efficiency.

\subsection{CFD grid deformation}

The RBF has been demonstrated that this method can produce high quality meshes which are very suitable for aeroelastic CFD codes [27]. Based on the RBF, if the number of the surface grid points is $N$, there are $N$ equations for each point needs to be solved:

$s\left(r_{i}\right)=d_{i}$

where, $d_{i}$ is the known value of the displacement at the boundary, which is also the result of interpolation from the structural nodal displacement to the displacement of CFD surface points. Moreover, there are additional requirements:

$\sum_{i=1}^{N} \alpha_{i} r_{i}=0$

Once $\alpha_{i}$ is determined, and then substituting it into eq. (5) can obtain the displacement of the space points of all the CFD grids.

Mesh motion using RBF method has been tested and it is successfully demonstrated for $10^{7}$ cell structured mesh.

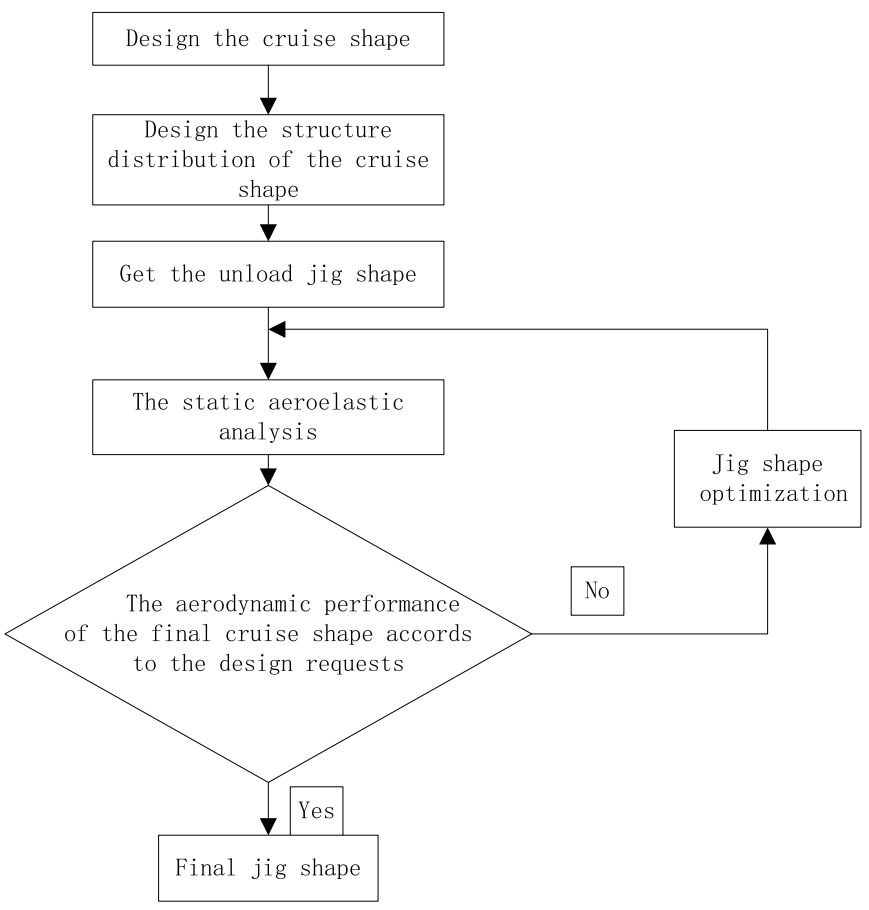

Fig. 2. The ordinary jig shape design process.

\section{Jig shape design method}

The airplane structure has elastic distortion due to the aerodynamic force, engine thrust and gravity. The jig shape deforms to the cruise shape under the steady cruise condition.

$q=[C](f+g+t)$

where $g$ is the gravity, and $t$ the thrust.

During a jig shape design procedure, designing the aerodynamic shape is the first step, by which a tested cruise shape is get and then the jig shape is designed based on it. Under the hypothesis of small amount of elastic deformation, the jig shape design load is in the opposite direction of the static aeroelastic load basically, such as equation (10) shows:

$q^{\prime}=[C](-f-g-t)$

which means the jig shape is the result of putting the aerodynamic force, gravity and thrust on the structure on the negative direction of the original ones when knowing the designed cruise shape. This kind of jig shape (the unloaded jig shape) achieves the design purpose and it has effective aerodynamic performance.

However, the unloaded jig shape could not be manufactured technically in most cases or it is not perfect at some spots on the flight envelope. So, this jig shape needs to be optimized until the final shape satisfy all of the design requirements. The ordinary jig shape design method depicts in Fig. 2, which includes following optimization steps:

1) Designing the cruise shape under the cruise aerodynamic requirements;

2) Applying the cruise load with the negative direction on the cruise shape to obtain the unloaded jig shape;

3) Performing static aeroelastic simulation of the jig shape to obtain a real cruise shape;

4) If the aerodynamic performance of the real cruise shape could not satisfy the design requirements, the jig shape will be optimized again, and return back to step 3); 


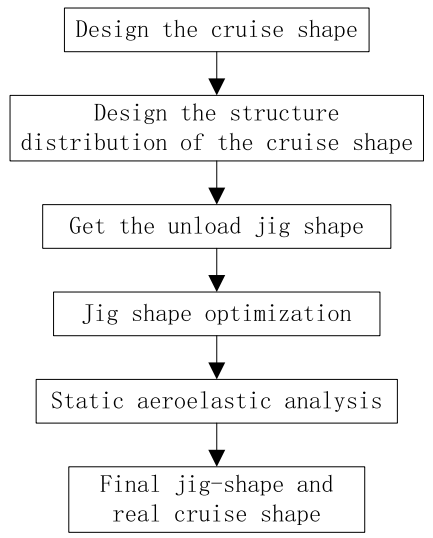

Fig. 3. Jig shape design process in this paper.

5) If the aerodynamic performance of the real cruise shape could meet the design requirements, the iteration ends.

This paper develops a new jig shape design method. As shown in Fig. 3, there is only one optimization step included.

There is a reference line on the wing due to the requirement of the manufacture. This reference line could be a straight line, several straight lines, a curve or several curves, which are used to locate structural components. The reference points are on the reference line at different wing sections. For example, line of the leading edge could be the reference line.

The optimal jig shape is obtained through two optimization steps:

1) Optimization step 1: Calculate the location of the wing sections of the unloaded jig shape, then move the sections along $x, y, z$ directions until the reference points are at the same place of those on the designed cruise shape based on the unloaded jig shape. It is important to make promise of that the twist of these sections is the same as that of the unloaded jig shape. As shown in Fig. 4, the twist angle of the jig shape after optimization step 1 is the same as the unloaded jig shape. The cut section of the jig shape after optimization step 1 and that of the designed cruise shape overlap at the reference point (at the leading edge or the beam).

2) Optimization step 2: Just as Fig. 5 shows, find out the wing section that has the greatest lift of the designed cruise shape, and calculate its displacement at the point on the reference line. So that to get the angle $\Gamma$ formed by the section before and after unloading, then change dihedral angle $\Gamma$ of the wing down based on the jig shape in optimization step 1 .

Many tests have been performed to validate these two optimization steps. The optimization step 1 is to achieve the manufacture requirement. After the optimization step 1, the twist angle of every section of the real cruise shape is almost the same as the designed one. The twist angle of the wing sections decides the lift and drag of the wing if the other conditions are the same, so the aerodynamic performance of the real cruise shape is almost the same as the designed cruise shape. The optimization step 2 is to get a real cruise shape that is close to the designed cruise shape. After the optimization step 1, the real cruise shape is much different from the designed one even though they have the same aerodynamic performance on the cruise state. That brings bad performance at different design points of the flight envelope even the stall in dangerous situation. After the optimization step 2, the sections with the largest lift of the real cruise shape and the designed cruise shape overlap each other, so that they are similar to each other. In addition, the sections that provide high lift are almost at the same place.

There is validity of these two optimization steps in the design process for a baseline vehicle in the next section.

\section{Jig shape design for a baseline vehicle}

\subsection{The designed aerodynamic cruise shape}

The baseline vehicle selected for the study is a notional singleaisle, mid-size aircraft. The illustration of the baseline vehicle is shown in Fig. 6. There are 610 blocks of the multi-block meshes of the design cruise shape of and the total number of the meshes is about 15 million. Fig. 7 shows the spatial meshes and the wall meshes. The structure model is established based on the aerodynamic shape design as shown in Fig. 8. There are 20000 nodes and 27000 elements in the finite element model, which is established by commercial code Patran.

\subsection{Validation of the jig shape design method}

To validate the jig shape design method, many cases have been tested on an IBM power 755 computer. There are four significant cases illustrated here:

1) Case 1: An aerodynamic CFD calculation of the designed cruise shape and the given lift is 0.52 , by which we get the design attack angle 1.934 degree on the cruise state.

2) Case 2: A static aeroelastic calculation of the designed cruise shape and the attack angle is set to 1.934 degree.

3) Case 3: A static aeroelastic calculation of the unloaded jig shape and the attack angle is set to 1.934 degree.

4) Case 4: A static aeroelastic calculation of the optimal jig shape and the attack angle is set to 1.934 degree.

Table 1 shows the lift and drag results of these cases. In Case 1 there are the results of the designed cruise state, the lift and drag of which are 0.5200 and 0.03114 . By comparing the lift and drag of Case 1 and Case 2, the static aeroelastic effect is very important because it changes about $21.7 \%$ of the aerodynamic performance.

\footnotetext{
- Designed cruise shape

............... Unloaded jig shape

Jig shape after optimization step 1
}

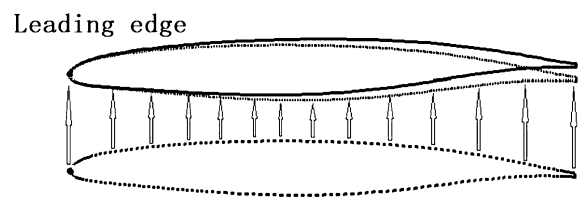

Leading edge

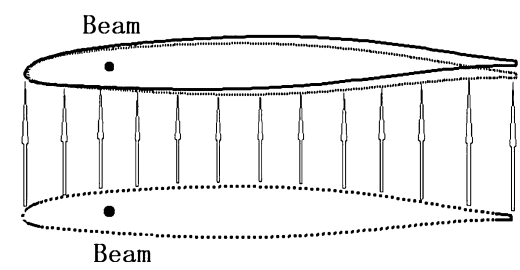

Fig. 4. Geometry movement in optimization step 1. 
Table 1

Lift and drag in test cases.

\begin{tabular}{lllllll}
\hline $\begin{array}{l}\text { Case } \\
\text { No. }\end{array}$ & Shape & $\begin{array}{l}\text { Rigid or } \\
\text { elastic }\end{array}$ & $\begin{array}{l}\text { Attach } \\
\text { angle }\end{array}$ & Lift & Drag & Lift/Drag \\
\hline 1 & Designed cruise shape & Rigid & 1.934 & 0.5200 & 0.03114 & 16.6988 \\
2 & Designed cruise shape & Elastic & 1.934 & 0.4071 & 0.02776 & 14.6650 \\
3 & Unloaded jig shape & Elastic & 1.934 & 0.5203 & 0.03114 & 16.7084 \\
4 & Optimal jig shape & Elastic & 1.934 & 0.5197 & 0.03112 & 16.6996 \\
\hline
\end{tabular}

By comparing the results of Case 1 and Case 3, the unloaded jig shape could achieve the lift and drag request after the static aeroelastic deformation, and the difference is only about $0.58 \%$. In addition, by the results of Case 1 and Case 4, the optimal jig shape achieves the aerodynamic requirement after deformation, and the difference is almost about $0.49 \%$. That means that both of the un-

The reference line on the designed cruise shape (after optimization step 1)

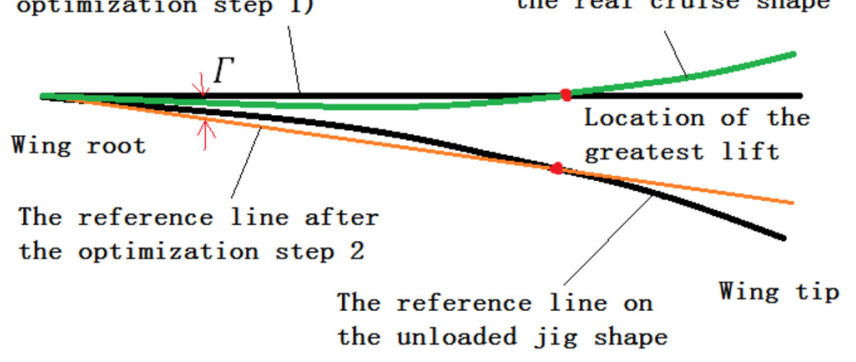

Fig. 5. Geometry movement in optimization step 2 .

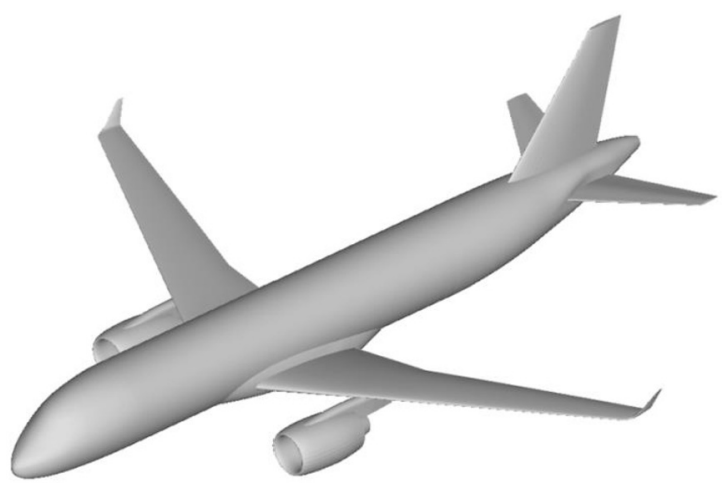

Fig. 6. Baseline aircraft

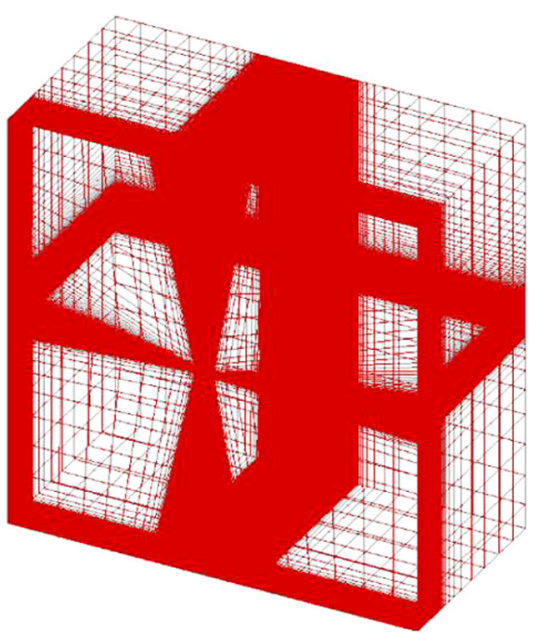

loaded jig shape and the optimal jig shape perform well under the cruise situation.

Fig. 9 shows the wing shapes of the designed cruise shape, the unloaded jig shape and their shapes after the deformation. If the designed cruise shape made technically, it will bend up into the blue shape in Fig. 9 when it is flying. Actually, the displacement increases gradually from the wing root to the tip, and the wing twist also increases gradually alone the reference line from the wing root to the tip. The biggest displacement at the wing tip is about $3.7 \%$ of the half span, and the biggest twist angle is about 1.6 degree. Importantly, after the static aeroelastic deformation, the unloaded jig shape is deformed, which almost overlaps the designed cruise shape exactly. Accordingly, there is a perfect real cruise shape if the unloaded jig shape manufactured. Moreover, it proves that the static aeroelastic calculation module is accurate.

As the description in optimization step 1, the position of each airfoil section of the unloaded jig shape has been adjusted such that its leading edge or a beam is at the same place of that on the cruise shape but the twist angle distribution is the same of the unloaded jig shape. A new jig shape is obtained and its basic aerodynamic performance is almost the same of the designed cruise shape. However, the real cruise shape is much different from the designed one because the elastic wing bends up until the force is balanced. Not only the cruise state is considered, but also different design points of the flight envelope are took into account during the design process of the given cruise shape. Because of the stalling characteristics and some other problems, the best real cruise shape should be close to the designed cruise shape. That is why the dihedral angle of the wing is changed in optimization step 2 . The results show that:

1) Change the dihedral angle -2.0 degree based on optimization step 1, Lift $=0.518791$, Lift/Drag $=16.6889$;

2) Change the dihedral angle -1.5 degree based on optimization step 1 , Lift $=0.520198$, Lift/Drag $=16.6972$.

Compared to the jig shape only with optimization step 1 after the static aeroelastic deformation (Lift $=0.521300$, Lift/Drag $=$ 16.7083 ), the difference is no more than $0.23 \%$. In addition, compared to the designed cruise state, the difference is $0.06 \%$. In conclusion, the aerodynamic performance of the final cruise shape is almost the same with the designed one with changing a little of the dihedral angle based on the optimization step 1.

Fig. 7. Structured meshes in CFD. 


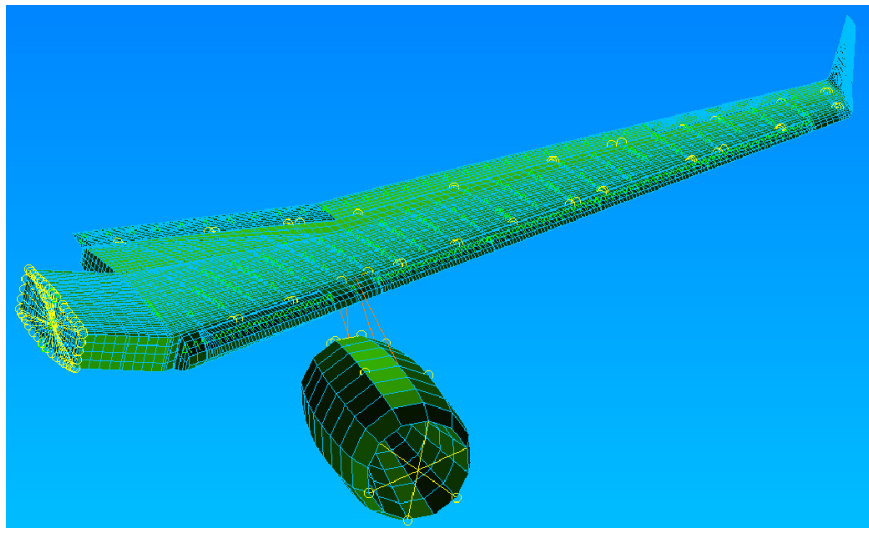

Fig. 8. Finite element model of the wing.

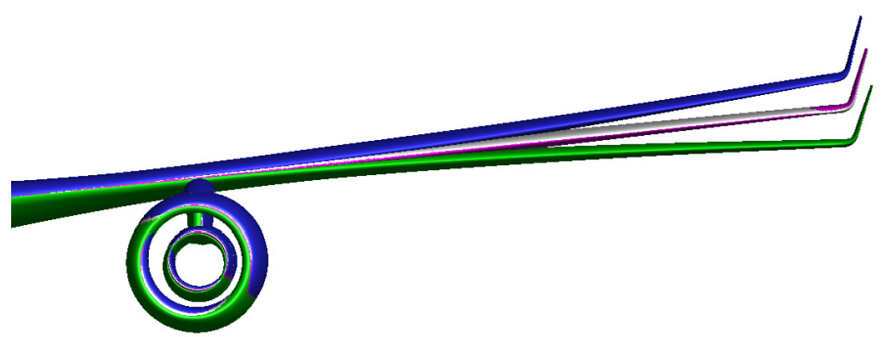

The unloaded jig shape after static aeroelastic deformation

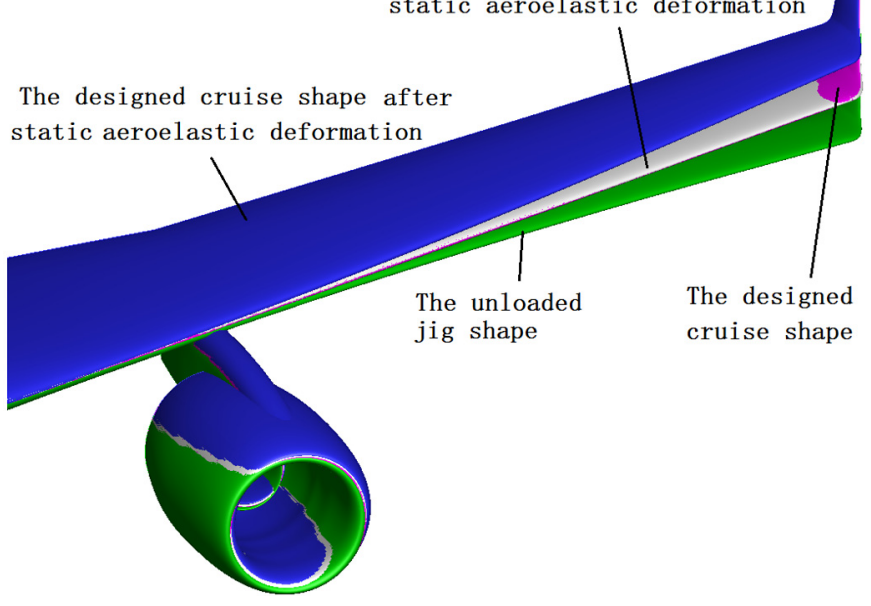

Fig. 9. The designed cruise shape and the unloaded jig shape. (For interpretation of the references to color in this figure, the reader is referred to the web version of this article.)

\subsection{The optimal jig shape design method}

According to the above analysis, a new optimization method of the jig shape design is proposed in this paper. During the aerodynamic design process, the sections nearby $70 \%$ of the wing is the key point because they provide the highest lift. There is an airfoil section the lift of which is at the top of the lift line, and it is at the middle of the high lift area almost. So optimization step 2 is used to get the final jig shape.

For the baseline vehicle, the location of the greatest lift $\mathrm{Cl}_{\max }=$ 0.6276 (66.15\% of the half span) as shown in Fig. 10. The dihedral angle $\Gamma$ in Fig. 5 is -1.4516 degree. Therefore, the optimal jig shape is shown in Fig. 11. After the static aeroelastic deformation, the gray wing is the final cruise shape. In addition, the real cruise shape and the designed cruise shape overlap at the section of $\mathrm{Cl}_{\max }$. The $\mathrm{Cl}$ of the real cruise shape is 0.519743 , and the $\mathrm{Cl} / \mathrm{Cd}$

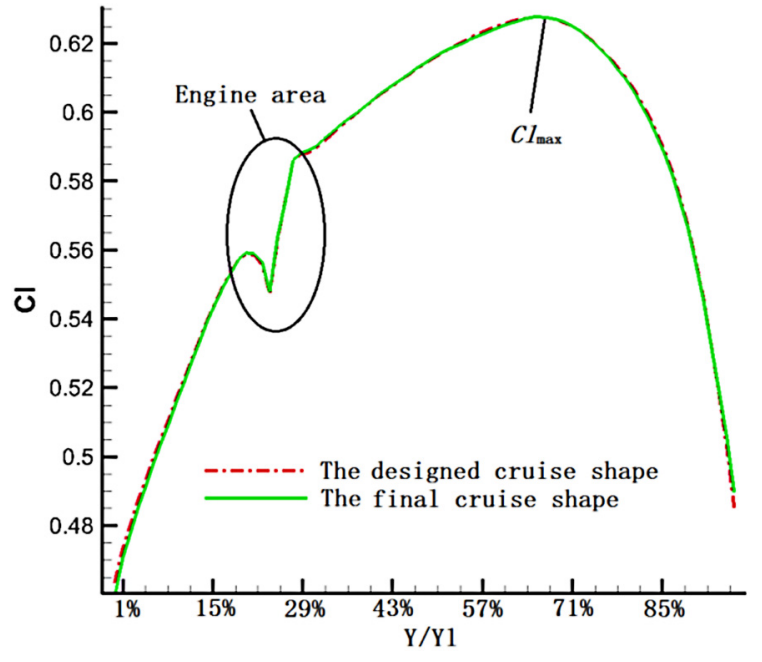

Fig. 10. Lift distribution at different wingspan section.

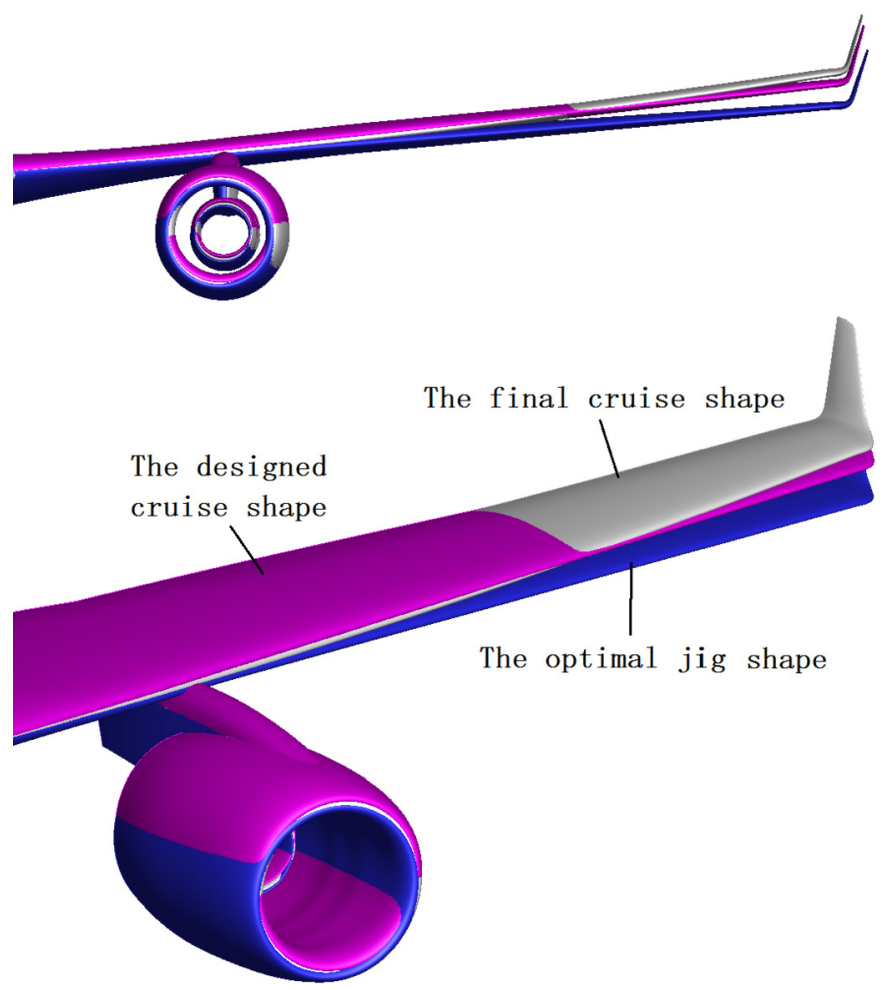

Fig. 11. The designed cruise shape, the optimal jig shape and the final cruise shape.

is 16.6996, which are close to the design data 0.5200 and 16.6988 . They are close to each other in shape, which means the optimal jig shape is better at the other design points on the flight envelope than the unloaded jig shape even if both of them can get good aerodynamic performance at the cruise state.

Fig. 10 shows the lift lines of the designed cruise shape and the real cruise shape (the optimal jig shape after the static aeroelastic deformation), apparently, the latter almost overlaps the former. Along the wing span from the wing root to the tip, $\mathrm{Cl}$ increases first and then decreases. The biggest $\mathrm{Cl}$ value is at about location $Y / Y l=66 \%$.

In Fig. 12 there are pressure distribution of the designed cruise shape, the unloaded jig shape after static aeroelastic deformation and the real cruise shape (the optimal jig shape after static aeroelastic deformation). 
There are pressure coefficient results of 21 airfoil sections in Fig. 13 for the optimize jig shape. Moreover, Fig. 14 shows the difference of the airfoils sections at different wing span locations. It is can be seen clearly that the pressure coefficient lines of the final cruise shape are almost the same of that of the designed cruise shape at most of the sections, which proves that the optimal jig shape achieves the design request in aerodynamic performance at the cruise state.

There are two important advantages of this jig shape design method:
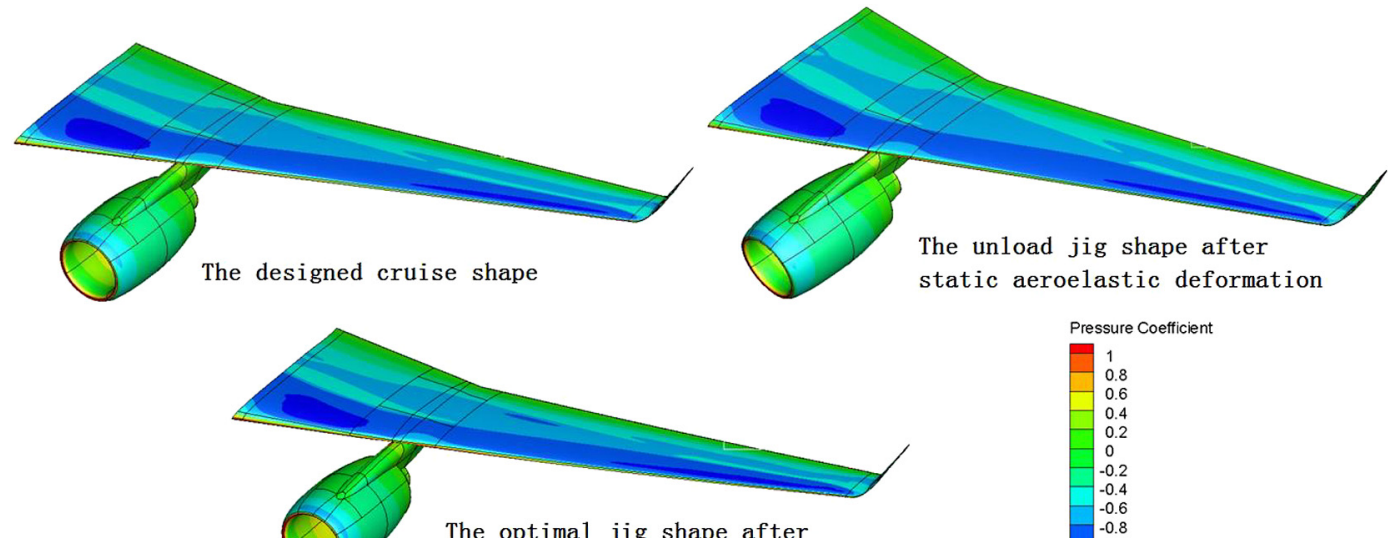

static aeroelastic deformation

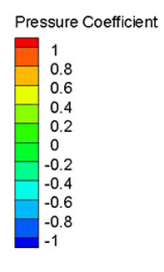

Fig. 12. The pressure coefficient distribution.

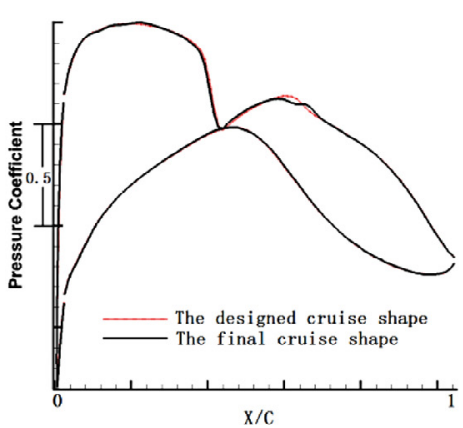

1) $5 \%$

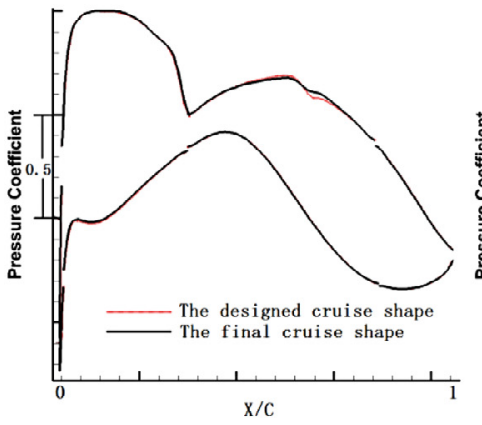

4) $20 \%$

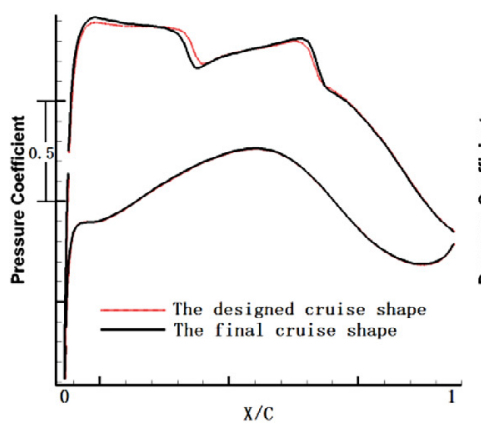

7) $40 \%$

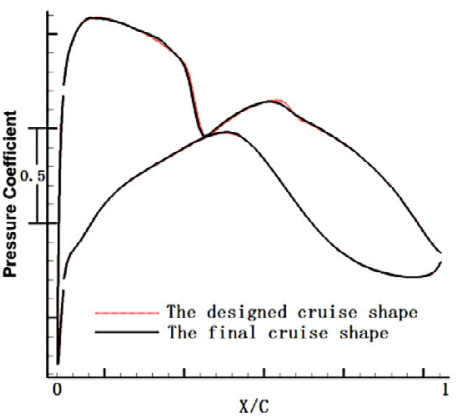

2) $10 \%$

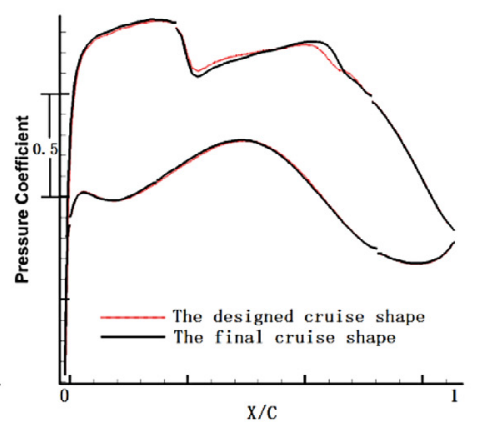

5) $30 \%$

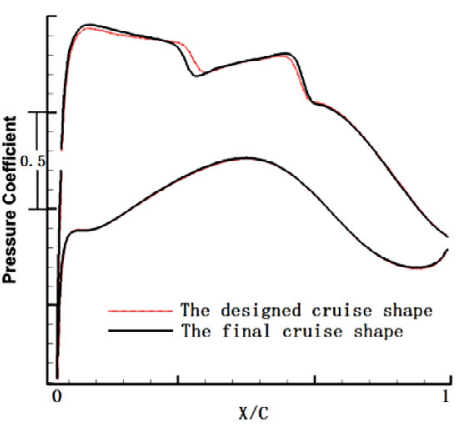

8) $45 \%$

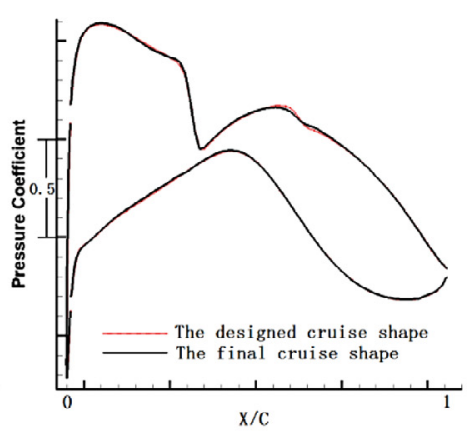

3) $15 \%$

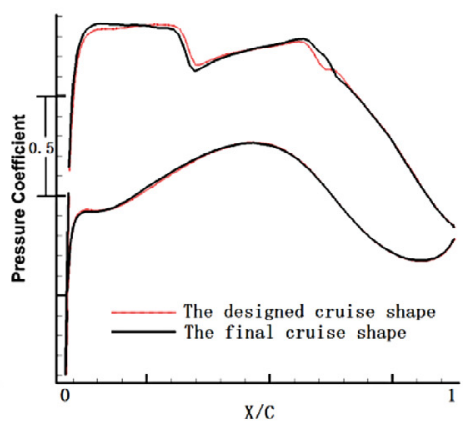

6) $35 \%$

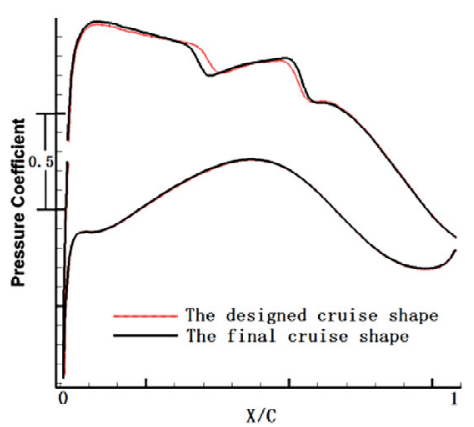

9) $49 \%$

Fig. 13. Pressure coefficient distribution. 


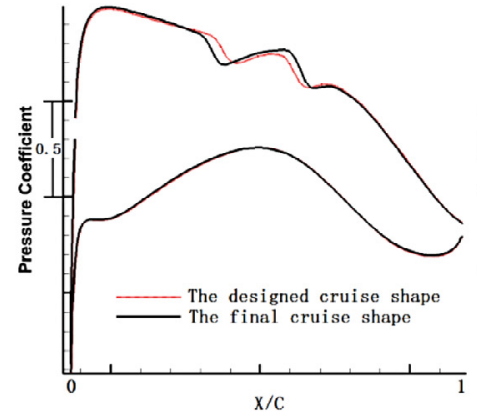

10) $53 \%$

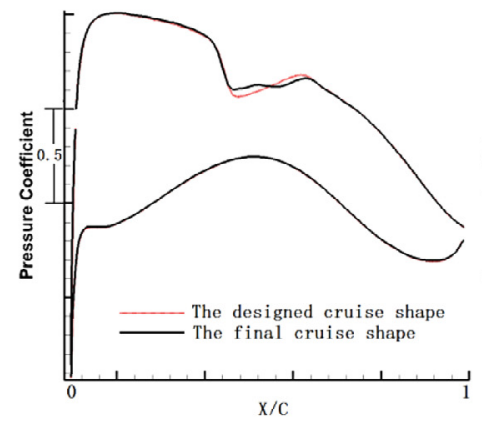

13) $66 \%$

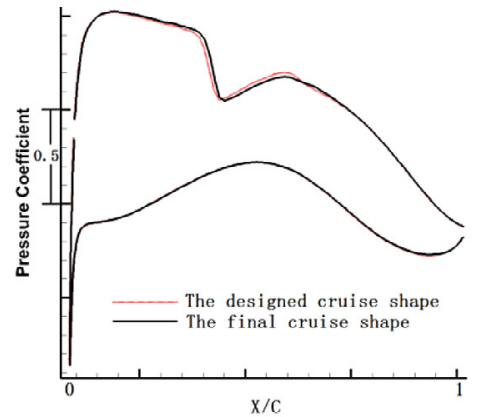

16) $78 \%$

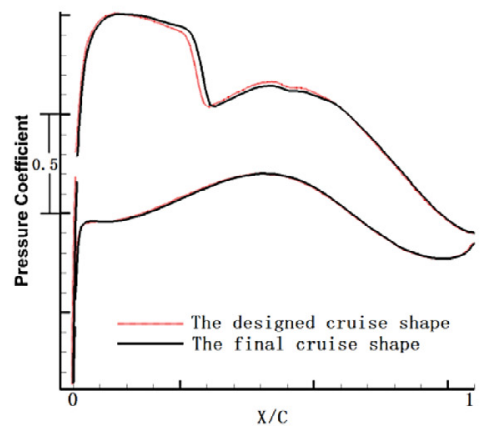

19) $90 \%$

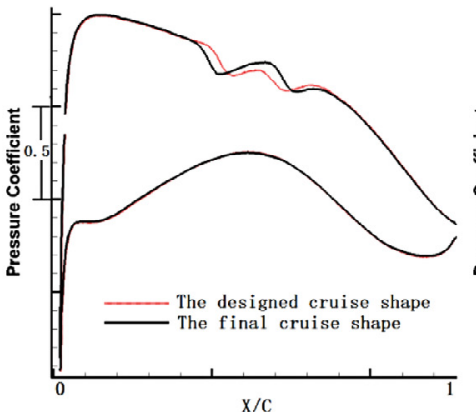

11) $57 \%$

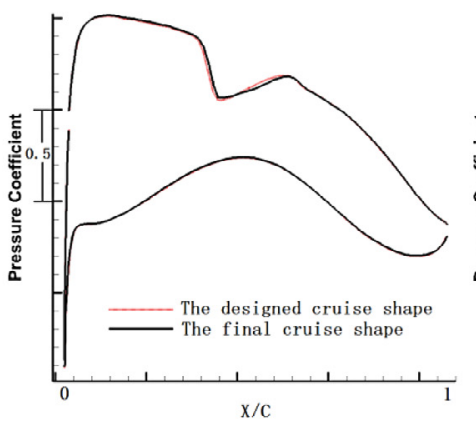

14) $70 \%$

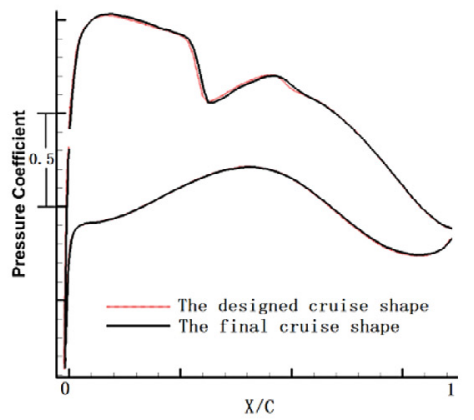

17) $82 \%$

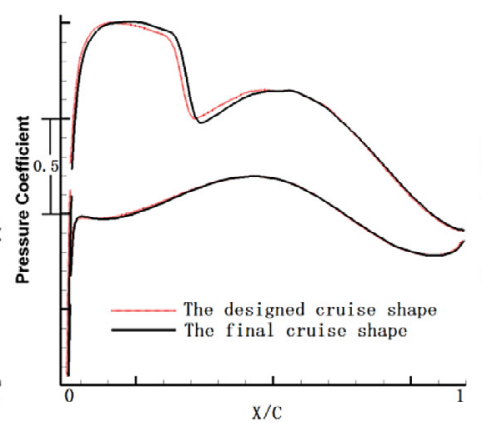

20) $92 \%$

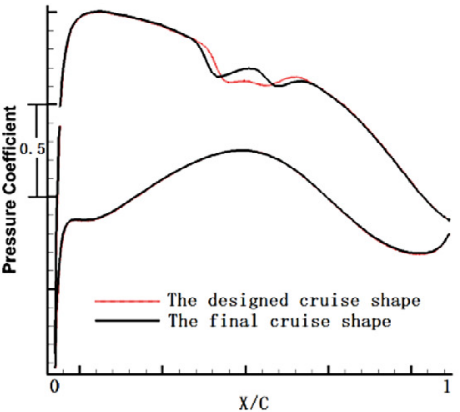

12) $61 \%$

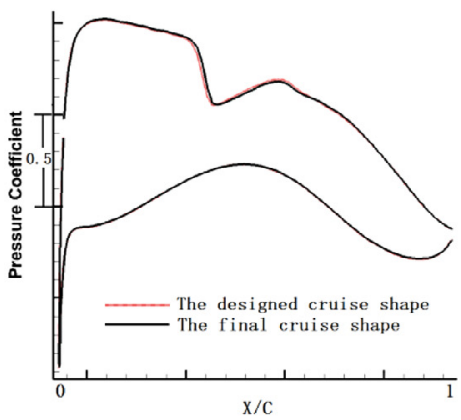

15) $74 \%$

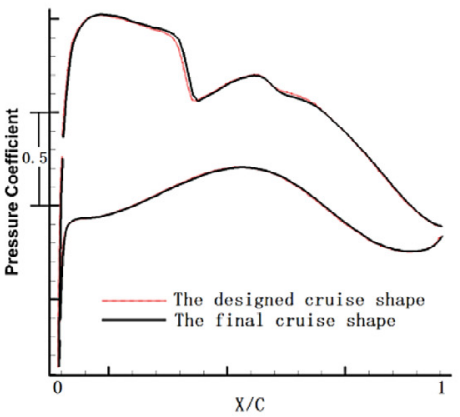

18) $86 \%$

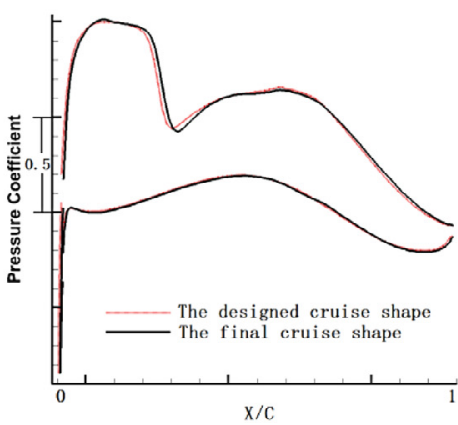

21) $94 \%$

Fig. 13. (continued)

1) Calculation precision: N-S equations are solved in CFD aerodynamic calculation, so the calculation precision is much better than that methods which use Euler equations. Moreover, the flexibility matrix is changed according to every new aerodynamic shape in each iteration so the calculation precision in deformation is good.

2) Computation speed: the CFD module takes about 95\% computation time in every iteration of the static aeroelastic sim- ulation. Structure grids are adopted to solve the N-S equations. In addition, two exact optimization steps instead of optimization of several wing geometry parameters save the time of iteration. The time of a jig shape design process with 15 million grids is about 1 hour on 96 CPUs. The time of a static aeroelastic calculation with the same number of grids is about 5 hours on 96 CPUs. That is very short in design methods with high precision CFD calculation methods. 
N

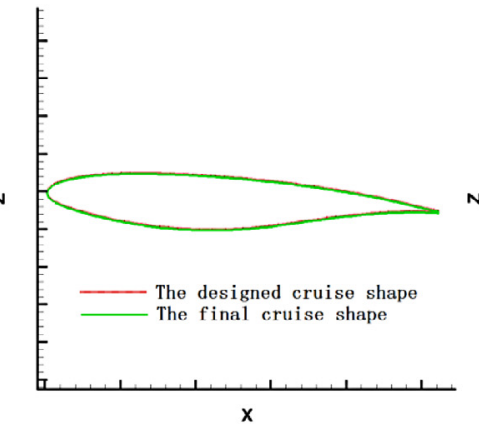

1) $5 \%$

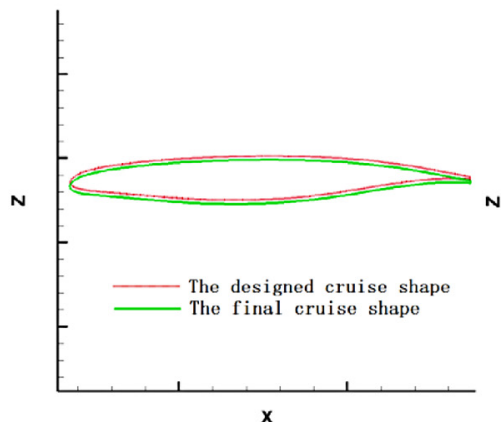

4) $61 \%$

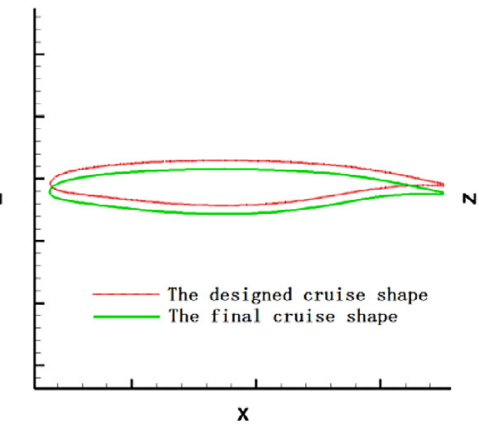

2) $35 \%$

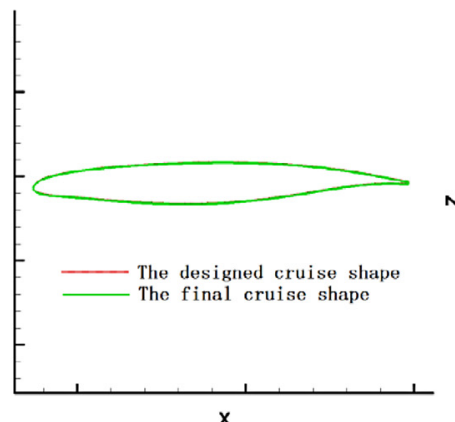

5) $66 \%$

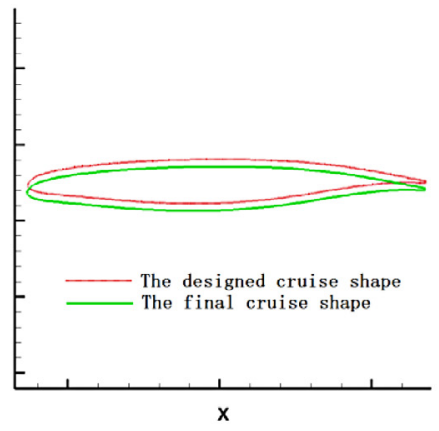

3) $53 \%$

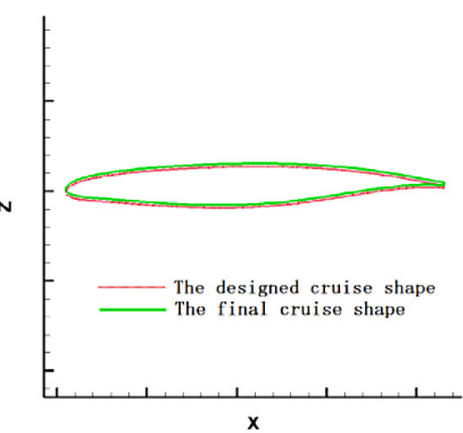

6) $70 \%$

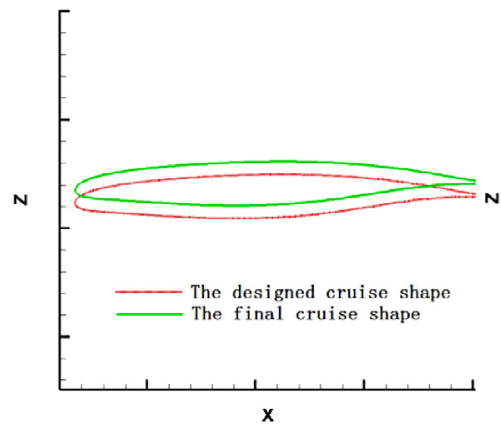

7) $78 \%$

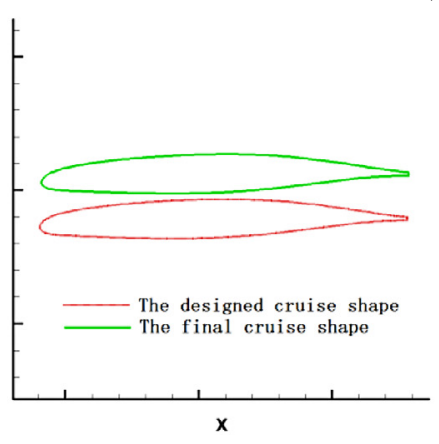

8) $94 \%$

Fig. 14. Airfoil comparison at different sections.

\section{Conclusion}

An effective airplane jig shape design method is presented in this paper. A bunch of analysis modules have been developed to formulate the whole design process, which includes the high precision structured mesh CFD calculation module, flexibility matrix calculation module, high precision three-dimensional interpolation module, and RBF grids deformation module. At first, the cruise load is applied in the opposite direction to the cruise shape to obtain the unloaded jig shape based on designed cruise aerodynamic requirements. Then, the locations of the wing sections of the unloaded jig shape are determined, and adjusted along $x, y, z$ directions until the reference points are at the same place of those on the designed cruise shape based on the unloaded jig shape. After that, the angle $\Gamma$ formed by the section with the largest lift before and after unloading is predicted, and then to down lower this dihedral angle. Finally, static aeroelastic simulation of the jig shape is performed to obtain a real cruise shape. Numerical simulations show that the whole CPU time cost for the simulation of a baseline airplane with 15 million CFD grids and 20000 CSD nodes is about 6 hours on 96 CPUs. The pressure coefficient lines of the final cruise shape are almost the same of those of the designed cruise shape at most of the sections. The optimal jig shape achieves the design requirements in aerodynamic performance at the cruise state, and the real cruise shape is similar to the designed cruise shape.

\section{Conflict of interest statement}

We declare that we do not have any commercial or associative interest that represents a conflict of interest in connection with our work.

\section{References}

[1] L. Reimer, C. Braun, J. Ballmann, Analysis of the static and dynamic aerostructural response of an elastic swept wing model by direct aeroelastic simulation, in: Annual Meeting of the International Council of the Aeronautical Sciences, Hamburg, Germany, 2006

[2] J.C. Newman III, P.A. Newman, A.C. Taylor III, et al., Efficient nonlinear static aeroelastic wing analysis, Comput. Fluids 28 (4-5) (1999) 615-628.

[3] A. Fazzolari, N. Gauger, J. Brezillon, Efficient aerodynamic shape optimization in MDO context, J. Comput. Appl. Math. 203 (2007) 548-560.

[4] B.H.K. Leea, S.J. Priceb, Y.S. Wong, Nonlinear aeroelastic analysis of airfoils: bifurcation and chaos, Prog. Aerosp. Sci. 35 (3) (1999) 205-334.

[5] L. Thomas, H. Andreas-René, Influence of wing elasticity on dynamic derivatives of transport aircraft, in: 48th AIAA Aerospace Sciences Meeting Including the New Horizons Forum and Aerospace Exposition, Florida, 2010, AIAA 2010-398.

[6] C. Farhat, P. Geuzaine, G. Brown, Application of a three-field nonlinear fluidstructure formulation to the prediction of the aeroelastic parameters of an F-16 fighter, Comput. Fluids 32 (1) (2003) 3-29. 
[7] C.V. Spain, J. Heeg, T.G. Ivanco, et al., Assessing videogrammetry for static aeroelastic testing of a wind-tunnel model, in: 45th AIAA/ASME/ASCE/AHS/ASC Structures, Structural Dynamics and Materials Conference, Spain, 2004.

[8] M.G. Gregory, B.R. Melissa, L.G. Scott, et al., Experimental investigation of the DLR-F6 transport configuration in the national transonic facility, in: 26th AIAA Applied Aerodynamics Conference, Hawaii, 2008, AIAA 2008-6917.

[9] A.B. Danny, Videogrammetric model deformation measurement technique for wind tunnel applications, in: 45th AIAA Aerospace Sciences Meeting and Exhibit, Nevada, 2007, AIAA 2007-1163.

[10] E. Oktay, H.U. Akay, O. Merttopcuoglu, Parallelized structural topology optimization and CFD coupling for design of aircraft wing structures, Comput. Fluids 49 (1) (2011) 141-145.

[11] X. Huang, J. Dudley, R.T. Haftka, et al., Structural weight estimation of multidisciplinary optimization of high speed civil transport, J. Aircr. 33 (3) (1996) 608-616.

[12] D. Raveh, M. Karpel, Structural optimization of flight vehicles with computational-fluid-dynamics-based maneuver loads, J. Aircr. 36 (6) (1998) 1007-1015.

[13] D.J. Neill, D.L. Herendeen, Automated Structural Optimization System (ASTROS), TR-93-3025, U.S. Air ForceWright Aeronautical Lab, Dayton, 1993.

[14] L. Cavagna, S. Ricci, L. Travaglini, NeoCASS: an integrated tool for structural sizing, aeroelastic analysis and MDO at conceptual design level, Prog. Aerosp. Sci. 47 (8) (2011) 621-635.

[15] M. Karpel, B. Moulin, M. Love, Structural optimization with static aeroelastic and stress constraints using expandable modal basis, AIAA J. 37 (11) (1999) 1514-1519.

[16] M.D. Kulkarni, R.A. Canfield, M.J. Patil, et al., Integration of geometric sensitivity and spatial gradient reconstruction for aeroelastic shape optimization, in: Maryland 10th AIAA Multidisciplinary Design Optimization Conference, National Harbor, 2014, AIAA 2014-0470.
[17] A. Jameson, K. Leoviriyakit, S. Shankaran, Multi-point aero-structural optimization of wings including planform variations, in: 45th Aerospace Sciences Meeting and Exhibit, Nevada, 2007, AIAA 2007-764.

[18] P.J. Rohl, D.N. Mavris, D.P. Schrage, Combined aerodynamic and structural optimization of high speed civil transport wing, in: 36th AIAA/ASME/ASCE/AHS/ ASC Structures, Structural Dynamics and Materials Conference, Washington, DC, 1995, pp. 548-557.

[19] S. Aly, M. Ogot, R.B. Pelz, et al., A decoupled stochastic approach to the jigshape aeroelastic wing design problem, in: 36th Aerospace Sciences Meeting \& Exhibit, Nevada, 1998, AIAA 98-0906.

[20] N. Nhan, T. Khanh, R. Kevin, Elastically shaped wing optimization and aircraft concept for improved cruise efficiency, in: 51st AIAA Aerospace Sciences Meeting Including the New Horizons Forum and Aerospace Exposition, Texas, 2013, AIAA 2013-0141.

[21] Z. Wan, L. Liang, C. Yang, Method of the jig shape design for a flexible wing, J. Aircr. 51 (1) (2014) 327-330.

[22] P.C. Chen, Z. Zhang, E. Livne, Towards CFD based aeroservoelastic flight vehicle shape optimization-new capabilities and new results with ZEUS-DO, in: 53rd AIAA/ASME/ASCE/AHS/ASC Structures, Structural Dynamics and Materials Conference, Hawaii, 2012, AIAA 2012-1561.

[23] T.C.S. Rendall, C.B. Allen, Unified fluid-structure interpolation and mesh motion using radial basis functions, Int. J. Numer. Methods Eng. 74 (2008) 1519-1559.

[24] T.C.S. Rendall, C.B. Allen, Efficient mesh motion using radial basis functions with data reduction algorithms, J. Comput. Phys. 228 (2009) 6231-6249.

[25] M. Buhmann, Radial Basis Functions, first ed., Cambridge University Press, 2005.

[26] H. Wendland, Scattered Data Approximation, first ed., Cambridge University Press, 2005.

[27] A. Boer, M.S. van der Schoot, H. Bijl, Mesh deformation based on radial basis function interpolation, Comput. Struct. 85 (2007) 784-795. 